\title{
Understanding the Downward Extension of Psychopathy to Youth: Implications for Risk Assessment and Juvenile Justice
}

\author{
Michael J. Vitacco and Gina M. Vincent
}

Psychopathy is an important construct in adult risk assessment resulting from strong associations to antisocial behavior and criminal recidivism. A recent trend is the downward extension of psychopathic traits to explain juvenile violence. Applying the concept of psychopathy to youthful offenders has great potential; however, its application to adolescence is fraught with uncertainty. This article discusses how the search for causes of violence along with the changing juvenile justice system have encouraged psychopathy to be used for informing policies related to the assessment and treatment of juvenile offenders. Based on established research and clinical practice, we make the case that if applied judiciously, psychopathy can be a critical component in identifying youth most at-risk for short-term violence.

Psychopathy is defined by a "constellation of affective, interpersonal, and behavioral characteristics, including egocentricity; impulsivity; irresponsibility; shallow emotions; lack of empathy, guilt, or remorse; lying; manipulativeness; and the persistent violation of social norms and expectations" (Hare, 1996, p.25). This combination of personality and behavioral traits has been identified as a putative risk factor for violence in civil psychiatric patients (Vitacco, Neumann, \& Jackson, 2005), spouse abusers (Goodman, Dutton, \& Bennett, 2000), and sex offenders (Harris, Rice, \& Quinsey, 2003). As such, psychopathy has become the preeminent construct employed in violence risk assessments (Hemphill, Hare, \& Wong, 1998; Salekin, Rogers, $\&$ Sewell, 1996). However, the use of psychopathy has transcended basic risk assessment and instead has been used to predict violence with certitude. Such examples include using psychopathy to support capital punishment (Edens, 2001) or for commitment to secure settings (Schopp \& Slain, 2000). These examples only serve to highlight potential consequences of using psychopathy in clinical settings and underscore the need to apply caution when communicating the results of psychopathy assessments.

The concern for potential misapplication or destructive application is magnified when extending psychopathy downward to children and adolescents.
This downward extension has significant ramifications for youth involved in litigious situations, including the transfer of adolescents to adult court (Penney \& Moretti, 2005). Not surprisingly, the application of psychopathy to these types of cases has generated significant controversy and has raised the question if the construct should be used in any decision-making capability for children and adolescents. From this controversy, one facet is clearly noted; the downward extension of psychopathy to child and adolescent offenders to support long-term placement or legal judgments is not sufficiently established in the literature (Hart, Watt, \& Vincent, 2002; Seagrave \& Grisso, 2002). Nonetheless, psychopathy continues to be employed in evaluations with youthful offenders, placing significant onus on the clinician to provide safeguards to insure the construct is not misused.

This article will explore the rise of psychopathy as a construct utilized in violence risk assessment with juvenile offenders. We further discuss developmental limitations associated with applying a construct originally designed to be used with adults to children and adolescents. Finally, we outline limitations in current knowledge and provide a set of recommendations for ethically assessing psychopathy with adolescent offenders within the context of risk assessment.

Michael J. Vitacco, Mendota Mental Health Institute, Madison, Wisconsin; Gina M. Vincent, University of Massachusetts Medical School, Worcester, Massachusetts. We would like to acknowledge Drs. Thomas Grisso and Michael Caldwell for their comments on an earlier draft of this paper.

Correspondence concerning this article should be addressed to Michael Vitacco, Ph.D., Mendota Mental Health Institute, Madison, WI 53704, Ph (608) 301-1518 (E-mail: vitacmj@dhfs.state.wi.us). 


\section{PSYCHOPATHY'S EXTENSION TO YOUTH}

One of the most stimulating, albeit controversial aspects of psychopathy research and clinical practice has been its downward extension to children and adolescents. Many scholars have posited that it may not be possible to measure psychopathy, or any personality disorder for that matter, reliably and validly prior to adulthood due to maturation and subsequent changes in personality (see Mash \& Dozois, 2003). Although these positions have led to questions regarding the application of psychopathy to at-risk youth, the application of psychopathy to youth continues to grow. For instance, a literature search revealed 15 sources pertaining to adolescent psychopathy between the years of 1992 and 1994; however, 10 years later that number increased to over 70. This $400 \%$ increase provides an illustrative example of the increased attention allotted to the study of youth psychopathy. In explaining this increase, we discuss two primary reasons that underscore the increase of psychopathy to adolescent offenders, including (1) an increased focus on etiological theories of psychopathy to explain youth violence and (2) the increasingly punitive juvenile justice system.

\section{ETIOLOGY: SEARCHING FOR CAUSES OF JUVENILE VIOLENCE}

As youth psychopathy research burgeoned, theories were developed attempting to explain youthful offenders who, at first glance, resemble adult psychopathic offenders in both antisocial behavior and the subsequent lack of remorse for their behavior. Significant rhetoric has been directed toward adolescents with psychopathic traits. For instance, Kellerman (1999) wrote, "Sometimes a psychopathic child's cruelty tops off at the level of school yard bullying. But often it doesn't, because domination, like any narcotic, breeds satiation and habituation. When first shoving, then hurting, and then raping cease to provide a sufficiently potent thrill, the game can swell, peaking at the ultimate control scheme" (p. 23). Given such dramatic descriptions it would appear to be in everyone's best interest if psychologists could identify 'fledgling psychopaths' in order to prevent future acts of violence.
Evaluating psychopathic traits from a developmental perspective offers a great opportunity for improving our understanding of this condition (Salekin \& Frick, 2005). To that end, we examine two areas of research that focus on explaining psychopathic traits in youth: externalizing disorders and callous/unemotional traits. These two theories warrant discussion because of their frequent citation in current psychopathy research. In addition, we discuss how the changing juvenile justice system has led to an increased focus on concepts related to youth psychopathy.

a. Externalizing Disorders and Psychopathy. In a series of articles, Lynam (1996, 1997, 1998) identified characteristics of the "fledgling psychopath." Based on research by Loeber and colleagues (Loeber \& Dishion, 1983), Lynam proposed a cluster of behavioral characteristics including hyperactivity, impulsivity, and attention deficits (i.e., HIA) that when combined with conduct problems created a "nomological net" that could be used to identify early psychopaths. Adolescents with HIA-CP were proposed to have similar neuropsychological deficits as adult psychopaths. These specific deficits were proposed to support continuity in psychopathic behavior from adolescence to adulthood. Piatigorsky and Hinshaw (2004) discovered psychopathy to be related to ADHD, conduct problems, and oppositional defiant disorder in a sample of adolescents. In a recent review, Lynam and Gudonis (2005) discussed a model of escalation whereby early symptoms of HIA lead to increasing levels of conduct problems. This theory is especially salient as it linked early dysfunction to long-term violent behavior. Notably, recent evidence has found associations between various externalizing behaviors (e.g., substance use) and psychopathy in adult offenders (see Patrick, Hicks, Krueger, \& Lang, 2005).

b. Callous/Unemotional Traits. Studying callous traits to identify at-risk youth has become a large part of developmental psychopathy research (Dadds, Fraser, Frost, \& Hawes, 2005; Frick, 2006). Frick (1998) proposed that poor behavioral inhibition led to the development of a callous and unemotional (CU) personality forming the basis for the emergence of psychopathy. In supporting this thesis, Christian, Frick, Hill, Tyler, and Frazer (1997) found children with callousness and impulsivity had significantly more police contacts and school problems than 
children with impulsivity alone. In a similar vein, Vitacco, Rogers, and Neumann (2003) found adolescents with substantial criminal records and placement in a maximum-security facility had significantly higher levels of callous traits than adolescents incarcerated in minimum-security. Interestingly, the groups had equivalent levels of impulsivity. Like the HIA-CP model, searching for $\mathrm{C} / \mathrm{U}$ traits in youth has stimulated important etiological research focusing on dispositional factors (Blair, 1995) or exposure to violent environments (Porter, 1996) as causes leading to a diminished empathy. Not surprisingly, the $\mathrm{C} / \mathrm{U}$ model has generated substantial research aimed at identifying pathways leading to violence in children and adolescents (Frick et al., 2003).

\section{THE CHANGING JUVENILE JUSTICE SYSTEM}

The most significant change in the juvenile justice system in the past 20 years has been from a system emphasizing treatment and rehabilitation to one centered on incarceration and retribution (Grisso, 1998). While initially designed to deal with adolescent offenders based on the "special needs and immature status of young people emphasizing rehabilitation over punishment" (Steinberg \& Scott, 2003, p. 9) such courts, due to legislative action, have frequently lost jurisdiction over cases involving violence. The new juvenile courts no longer operate on the principle of "parens patriae" (Quinn, 1998); instead, they mirror societal trends by adopting a "get tough" stance on adolescent crime (Grisso, 1998). The primary rationale for said transfer is that adult courts are able to offer "more appropriate" (translate as more severe) penalties than their juvenile counterparts. As expected, much of the focus for transfer focuses on dangerousness and amenability to treatment (Salekin, Rogers, \& Ustad, 2001), concepts clearly intertwined with youth culpability and psychopathy.

\section{UNDERMINING THE RATIONALES FOR THE DOWNWARD EXTENSION}

Previous research has identified numerous shortcomings evident with the downward extension of psychopathy to children and adolescents. The primary thrust of the criticisms have centered on statistical shortcomings of predicting youth violence (Mulvey \& Cauffman, 2001), unreliable measurement of personality disorders in youth (Johnstone \& Cooke, 2004), and concerns over deficiencies in the primary models of adolescent psychopathy (Seagrave $\&$ Grisso, 2002). Each of these limitations severely undercuts support for applying models of psychopathy to explain and predict antisocial behavior in youth.

\section{Weaknesses of Etiological Theories}

a. Externalizing Disorders and Psychopathy. There are several problems with using externalizing disorders to identify psychopathic traits in youth. Primarily, using this model would result in an unacceptable number of false-positives since impulsivity, hyperactivity, and attention problems are common substrates among a large majority of juvenile offenders, even in adolescents charged with minor offenses. For instance, Vitacco and Rogers (2001) found that HIA was essentially unrelated to psychopathic traits in a sample of adolescents residing in a maximum-security facility. Moreover, deficits in HIA may not be specific to psychopathy, but instead more indicative of general psychopathology. Lambert, Wahler, Andrade, and Bickman (2001) found a host of symptoms, including both internalizing and externalizing disorders associated with conduct disorder. Therefore, if one casts a "nomological net" (Lynam, 1997) with HIA-CP, they will fail to identify adolescents truly at-risk for psychopathy. Vincent, Vitacco, Grisso, and Corrado (2003) demonstrated the large number of false positives associated with exclusively focusing on antisocial behavior in the absence of interpersonal and affective traits. Given the ominous connotations of classifying an adolescent as psychopathic, it is imperative to avoid Type II errors.

b. Callous/Unemotional Traits. The C/U model has been criticized primarily on the basis that many of its core features are a component of normative developmental processes and not, as suggested, the cornerstone of antisocial behavior (Seagrave \& Grisso, 2002). For instance, shallow affect and lack of remorse are common substrates in antisocial and nonantisocial youth, making it difficult to distinguish 
between an adolescent going through a normal developmental process and one who has the onset of a clinically significant disorder. Echoing these concerns, Johnstone and Cooke (2004) discussed the difficulty assessing psychopathy in children, especially in light of the maturation process demonstrated by rapid changes in moral development and conscience acquisition. On the whole, these studies raise serious questions regarding both the measurement and downward extension of psychopathic personality traits with children and adolescents.

\section{UNDERMINING THE USE OF PSYCHOPATHY IN TRANSFER PROCEEDINGS}

Using psychopathy to justify transfer to adult court or to advocate for lengthier sentences rests on two suppositions. First, it assumes that psychopathy begins early and remains stable to adulthood (Forth $\&$ Burke, 1998). Second, it relies on the notion that adolescent offenders with psychopathic traits are not amenable to treatment and remain a perpetual risk for violence. Notably, both these contentions seem largely unfounded and appear to rest more on scientific lore than empirical evidence. Early data suggesting that psychopaths get worse with treatment (Rice, Harris, \& Cormier, 1992) has been largely refuted. In contrast, treatment has been shown to reduce psychopathic traits in adolescents placed in a mental health unit (Rogers, Jackson, Sewell, \& Johansen, 2004) suggesting the risk of violence would also diminish. ${ }^{1}$ Caldwell, Skeem, Salekin, and Van Rybroek (in press) found significant decreases in violent behavior of adolescents after treatment in a maximum-security juvenile hybrid (correctional and treatment) facility with continued improvement over a two-year follow-up. Likewise, Salekin (2002) conducted a meta-analysis of 42 studies and discovered that severe conduct problems were reduced as a result of various therapeutic interventions. In looking at the temporal stability of psychopathy, Frick, Kimonis, Dandreaux, and Farell (2003) discovered that children high on psychopathic

\footnotetext{
${ }^{1}$ This supposition is valid only if psychopathy is related to shortterm risk in youth. Of note, Rogers et al. (2004) did not evaluate violence, only a change in psychopathy scores after receiving inpatient treatment.
}

traits were more likely to be rated lower over the course of a multi-year follow-up.

Based on these results, a high psychopathy score does not indicate automatic treatment failure nor certitude long-term violence. Based on the identified problems with measuring psychopathy in adolescence, Ells (2005) contended "the introduction of the diagnosis into the waiver decision is both premature and diagnostically unreliable" (p. 158). Clearly, transfer decisions based on psychopathy scores lack the necessary empirical backing to be considered valid indicators of long-term dysfunction ${ }^{2}$ (see Penney \& Moretti, 2005).

\section{DEVELOPMENTAL COMPLICATIONS IN ASSESSING YOUTH PSYCHOPATHY}

The climate in dealing with adolescent offenders has changed dramatically and has given rise to causal models explaining youth violence. However, the debate continues concerning the appropriateness of applying psychopathy to youth and the nature of psychopathic traits in youth. Many of these concerns stem from core issues in developmental psychopathology that naturally have been extended to psychopathy. These core issues include discontinuity, heterotypic continuity, and neurologic developmental issues. This section focuses on how each of these warrants consideration when constructing etiological pathways of psychopathy.

Discontinuity refers to the developmental mutability of pathways to the acquisition of various forms of psychopathology. The presence of a latent trait and the influence of many precursors to the disorder are not stable across early stages of development. Two concepts are used to express the complex pathways to development and remission of disorders among children and adolescents (Cicchetti \& Rogosch, 1996). Equifinality means that different pathways can lead to the same outcome. In other words, the same disorder, or healthy adjustment, can

\footnotetext{
${ }^{2}$ Feld (2000) discusses an alternative view whereby transfer to adult court and institutions acts as a safety valve protecting adolescents from dangerous peers. While we acknowledge this counterperspective we simply wish to point out that transfers simply facilitated on the basis of the instant offense(s) have not been empirically supported.
} 
be acquired through various pathways and different etiologies (Pervin, 2001). In the case of psychopathy, potential pathways include lax or neglectful parenting (Marshall \& Cooke, 1999), genetic predispositions (Viding, Blair, Moffitt, \& Plomin, 2005), brain abnormalities (Raine et al., 2003) or, more likely, a complex interaction among multiple factors. Multifinality refers to the notion that similar pathways can lead to different outcomes. Thus, a youth following an etiological pathway to psychopathy and expressing symptoms could instead develop one of a variety of other psychopathological conditions or remit and develop into an adult free of any psychopathology. Early expression of psychopathic personality in childhood are often transient (Angold, Costello, \& Erkani, 1999), can change dramatically over time, and may not predict adolescent or adult violence (see Rutter \& Stroufe, 2000).

An additional complication to the assessment of child psychopathology is the concept of heterotypic continuity, a key factor in the conceptualization and long-term assessment of severe antisocial behaviors (Moffitt \& Caspi, 2001). Heterotypic continuity refers to developmental changes in the expression of psychopathology. This highlights one problem with downward extensions of psychopathy measures to youth: Notably, phenotypic expression of psychopathic traits during childhood and adolescence may differ greatly from the phenotypic expression during adulthood. The consequences of heterotypic continuity can also work in the reverse. Youth free of any psychopathology can manifest behaviors, cognitions, and affects characteristic of psychopathy at various stages of adulthood. As such, adolescent psychopathy is complicated by both heterotypic continuity and discontinuity, thus limiting the predictive power of early behavior problems in predicting psychopathy in adulthood.

Research on neurophysiologic development has provided critical insights into the nature of developmental psychopathology, including the nature of psychopathy. In defining brain structures related to the expression of psychopathy, Blair (2003) implicated both the amygdala and frontal cortex areas. Moreover, neuropsychological deficits explain the lack of empathy, largely considered the central feature of psychopathy (Blair, 1995). Psychopathy as a brain-based disorder has important implications for understanding its lack of temporal stability in youth. Specifically, adolescence is widely regarded as a time of tremendous changes in maturity (Cauffman \& Steinberg, 2000), largely governed by maturation in brain mylenation during this critical period (Giedd et al., 1999). Given these changes in neural development, it is presumptive to speculate psychopathic-like behaviors will remain stable throughout the lifespan. (Seagrave \& Grisso, 2002) and research has not shed enough light on the longterm stability of psychopathic traits in adolescents.

\section{YOUTH PSYCHOPATHY, VIOLENCE, AND CRIMINALITY}

Despite serious sociocultural and developmental limitations, simply dismissing the value of youth psychopathy assessments would ignore a substantial body of literature demonstrating a link between the presence of psychopathic-like traits and juvenile violence. Multiple criterion-related validity studies have informed the debate about the relationship between psychopathic traits and youth violence, both retrospectively and prospectively. The bulk of research has focused on the Psychopathy Checklist: Youth Version (PCL:YV; Forth, Kosson, \& Hare, 2003). Short-term prospective studies of adolescent offenders have found the PCL:YV to predict both general and violent recidivism over follow-up periods averaging one to just over three years (e.g., Corrado, Vincent, Hart, \& Cohen, 2004). Retrospectively, Gretton, McBride, Hare, O’Shaughnessy, and Kumka (2001) reported strong associations between PCL:YV scores and recidivism across an average 5-year period. In an even longer "followback" period, higher scores on the PCL:YV were associated with higher violence over a maximum follow-up of 10-years (Gretton, Hare, \& Catchpole, 2004). Clearly, additional prospective studies are needed to evaluate the utility of psychopathic traits in predicting violent and aggressive behavior.

Though these findings appear promising for use of psychopathy measures in predicting risk for violence and criminality among adolescents, gaps in our knowledge remain. The few prospective studies that scrutinized the source of this high predictive validity by evaluating individual symptom clusters reported that the PCL:YV's predictive power 
stemmed primarily from behavioral traits (Corrado et al., 2004). Nonetheless, Vincent et al. (2003) found that adolescents scoring relatively high in each of the interpersonal, affective, and behavioral clusters were more likely to recidivate violently, and did so more quickly, than adolescents with behavioral features alone (see also, Christian et al., 1997 for similar findings with children). Ultimately, subtyping adolescent offenders may prove beneficial for developing treatment protocols that target specific traits of antisocial behavior. Subsequent research may also benefit from attempting to use psychopathic traits to subtype non-incarcerated youth (see Andershed, Gustafson, Kerr \& Stattin, 2002). Only through evaluating various populations can researchers and clinicians come to better understand the dimensional nature of psychopathy.

\section{CLINICAL IMPLICATIONS AND RECOMMENDATIONS FOR JUVENILE JUSTICE}

On the whole, the results from these studies indicate that despite many limitations, instruments for youth psychopathy have a place in assessing short-term risk for violence or general recidivism. While identification of psychopathy as a diagnostic entity is severely limited in adolescents, assessment tools appear to have validity for assessing risk for violence and distinguishing offenders for whom crime will be more imminent and frequent. However, developmental limitations of assessing psychopathy in youth create many potential problems. In light of this, we provide recommendations meant to serve as heuristics in guiding clinicians in the ethical practice of assessing and treating antisocial youth.

1. Avoid Diagnostic Labeling. The consequences associated with mislabeling an adolescent as a "psychopath" are potentially severe. In fact, the authors of the PCL:YV stated explicitly, "It is inappropriate for clinicians or other professionals to label a youth as a psychopath" (Forth et al., 2003, p.17). The problem is there are limited longitudinal data tracking the course and stability of psychopathic traits. Although retrospective studies provide evidence that most men who are psychopathic as adults had psychopathic symptoms by ages 6 to 10
(Loeber, Farrington, \& Petechuk, 2003), at least 50\% of children with pervasive and serious antisocial traits do not develop into antisocial adolescents or adults (Moffitt \& Caspi, 2001). In light of the dearth of longitudinal psychopathy research, we are currently unable to distinguish between phenotypically psychopathic youth with and without a stable disorder.

2. Conduct Comprehensive Assessments of Risk. Psychopathic traits in general, and PCL:YV scores in particular, are clearly linked to future violence and antisocial behavior among youth over short periods. However, the PCL:YV represents only one risk factor, not a comprehensive risk assessment, and must be used in conjunction with other risk factors or assessment tools. A few risk assessment tools incorporating the delinquency literature have been made available to practitioners (e.g., Youth Level of Service/Case Management Inventory, Hoge \& Andrews, 1999; the Structured Assessment of Violence Risk in Youth, Borum, Bartel, \& Forth, 2002; Early Assessment Risk List for Boys, Augimeri, Koegl, Webster, \& Levene, 2001). Psychopathy can and should play a role in comprehensive assessments, especially relating to the probability of short-term risk. Generally, high PCL:YV scores in youth, like high PCL-R scores in adults (Hart, 1998), may compel a conclusion of high risk over short periods of time.

3. Consider Protective Factors. In order to complete a comprehensive risk assessment one must consider a myriad of protective factors (Grisso, 1998; Rogers, 2000) that may allay risk, even in the presence of a high score on a measure of psychopathy. Several factors that protect adolescents from committing criminal acts have been identified including positive peer and parental influences, strong bonds to school, and participation in religious services (Herrenkohl et al., 2003). These factors must weigh in any comprehensive assessment of child or adolescent risk and should be listed individually. If clinicians are to engage in dynamic risk assessment protective factors must play a prominent role.

4. Conduct Multiple Assessments Across Time. Given that childhood and adolescence is a time of extreme developmental changes and psychopathy's relationship with developmental markers (e.g., maturity) remains unknown, clinicians are advised to assess psychopathic personality characteristics 
frequently in high risk youth to determine if the mere act of maturation attenuates risk. A single assessment of psychopathy is not appropriate for gauging prolonged risk. Unfortunately, due to the rating methods of psychopathy instruments, none of these measures are appropriate for measuring changes in traits over time. With respect to risk assessments in general, many tools allow for multiple assessments over time by documenting change. This approach is clinically warranted and necessary if the goal is to conduct a valid and ethical assessment of risk that accounts for the rapid psychosocial and brain developmental changes associated with adolescence.

5. Consideration of Environmental Influences. Psychopathy does not develop in a vacuum and there has been significant research positing a pathway between physical abuse and psychopathic traits. For instance, Porter (1996) posited pervasive physical abuse and neglect leads to decreased empathy and lack of conscience, both hallmarks of psychopathic traits. This connection between physical abuse, poor parenting, and variants of psychopathic traits has been discussed in the literature (see Frick, 1998). The underlying causes (equifinality) for the development of psychopathic-like features in adolescents should be explored during a clinical evaluation as pinpointing the origin may have a significant impact on potential treatment strategies.

6. Treatment Strategies Should Target Psychopathic Traits. Youth with psychopathic traits should be allotted intensive resources in order to maximize the potential to alter the trajectory to long-term offending. However, the constellation of psychopathic traits may affect the suitability of treatment modalities. For example, youth with predominately behavioral traits may be more likely to desist and be amenable to traditional juvenile justice treatment strategies (Vincent et al., 2003). Those with prominent callous/unemotional features may require innovative interventions. Ostensibly, effective interventions will be most crucial during early childhood if they are to impact the transition from childhood to early adolescence. Loeber et al. (2003) noted that, on average, the majority of severely antisocial youth begin their antisocial careers between the ages of 7 and 12. Since the juvenile justice system generally does not intervene until the ages of 10 to 13 at the earliest, Loeber et al. (2003) argued that the window for early prevention with the most serious youth is often missed. Rehabilitation efforts may be less effective ameliorating aberrant behavior in adulthood where antisocial behavior has become a "life-style".

7. Be Aware Other Inappropriate Uses of Psychopathy Assessments. According to the authors of the PCL:YV, psychopathy assessments are not for use in decisions pertaining to juvenile transfer to adult court or restricting access to treatment. Despite these cautions, information regarding psychopathy often plays a significant role in transfer decisions (Leistico \& Salekin, 2003; Penney \& Moretti, 2005). Professionals must be aware of potential misuses of psychopathy measures and not condone misapplications due to their potential devastating consequences. In fact, limitations of using psychopathy in juvenile evaluations (e.g., lack of long-term predictive power) must be candidly discussed in any evaluation where psychopathy is employed.

\section{CONCLUSION}

Predicting violence is a critical area for all mental health professionals who work with at-risk youth (Borum, 2000). Despite the fact it has been much maligned, the construct of juvenile psychopathy provides critical information when making informed decisions of risk. However, the discipline has much work to do before clinicians can be confident in their assessment of youth psychopathy. Although the field has continued to advance, adolescent risk assessment remains a relatively new endeavor fraught with uncertainty. Many questions remain unanswered, which only underscores the need for exercising extreme caution when assessing psychopathy in youth. Despite these concerns, we suggest that psychopathy can be used in a circumscribed fashion in the area of violence risk assessment, especially when the aim is to improve short-term clinical decision-making. Ultimately, the goal of mental health providers conducting risk assessments should be the protection of society within the context of ethical clinical practice. 


\section{REFERENCES}

Andershed, H., Gustafson, M. K., \& Stattin, H. (2002). The usefulness of self-reported psychopathy-like traits in the study of antisocial behavior among non-referred adolescents. European Journal of Personality, 16, 383-402.

Angold, A. E., Costello, J., \& Erkanli, A. (1999). Comorbidity. Journal of Child Psychology and Psychiatry, 40, 57-87.

Augimeri, L. K., Koegl, C. J., Webster, C. D., \& Levene, K.S. (2001). Early Assessment Risk List for Boys: EARL-20B (Version 2). Toronto, ON: Earlscourt Child and Family Centre.

Borum, R., Bartel, P., \& Forth, A. (2002). Manual for the Structured Assessment of Violence Risk in Youth (SAVRY). Tampa, FL: University of South Florida.

Blair, R. J. R. (1995). A cognitive developmental approach to morality: Investigating the psychopath. Cognition, 57, 129.

Blair, R. J. R. (2003). Neurological basis of psychopathy. British Journal of Psychiatry, 182, 5-7.

Borum, R. (2000). Assessing violence risk among youth. Journal of Clinical Psychology, 56, 1263-1288.

Caldwell, M. F., Skeem, J., Salekin, R., \& Van Rybroek, G. J. (in press). Treatment response of adolescent offenders with psychopathic features: A two-year follow-up. Criminal Justice and Behavior.

Cauffman, E., \& Steinberg, L. (2000). (Im)maturity of judgment in adolescence: Why adolescents may be less culpable than adults. Behavioral Sciences and the Law, 18, 741-760.

Christian, R. E., Frick, P. J., Hill, N. L., \& Tyler, L. (1997). Psychopathy and conduct problems in children II: Implications for subtyping children with conduct problems. Journal of the American Academy of Psychiatry and Law, 36, 233-241.

Cicchetti, D., \& Rogosch, F. A. (1996). Equifinality and multifinality in developmental psychopathology. Development and Psychopathology, 8, 597-600.

Corrado, R. R., Vincent, G. M., Hart, S. D., \& Cohen, I. M. (2004). Predictive validity of the Psychopathy Checklist: Youth Version for general and violent recidivism. Behavioral Sciences and the Law, 22, 5-22.

Dadds, M. R., Fraser, J., Frost, A., \& Hawes, D. J. (2005). Disentangling the underlying dimensions of psychopathy and conduct problems in childhood: A community study. Journal of Consulting and Clinical Psychology, 73, 400410.

Edens, J. F. (2001). Misuses of the Hare Psychopathy ChecklistRevised in court: Two case examples. Journal of Interpersonal Violence, 16, 1082-1093.

Ells, L. (2005). Juvenile psychopathy: The hollow promise of prediction. Columbia Law Review, 105, 158-208.

Feld, B. C. (2000). Legislative exclusion of offenses from juvenile court jurisdiction: A history and critique. In J. Fagan \& F.E. Zimring (Eds.), The changing borders of juvenile justice: Transfer of adolescents to the criminal court (pp. 83-132). Chicago: University of Chicago Press.

Forth, A. E., \& Burke, H. C. (1998). Psychopathy in adolescence: Assessment, violence, and developmental precursors. In D. J. Cooke, A. E. Forth, \& R. D. Hare (Eds.), Psychopathy:
Theory, research, and implications for society (pp. 205229). Dordrecht, The Netherlands: Kluwer.

Forth, A. E., Kosson, D. S., \& Hare, R. D. (2003). Hare Psychopathy Checklist: Youth Version Technical manual. Toronto: Multi-health Systems.

Frick, P. J. (2006). Psychopathy and developmental pathways to antisocial behavior in youth. In C. J. Patrick (Ed.), Handbook of psychopathy (pp.353-374). New York: Guilford.

Frick, P. J. (1998). Callous-unemotional traits and conduct problems: A two-factor model for psychopathy in children. In D. J. Cooke, A. E. Forth, \& R. D. Hare (Eds.), Psychopathy: Theory, research, and implications for society (pp. 205-229). Dordrecht, The Netherlands.

Frick, P. J., Cornell, A. H., Bodin, S. D., Dane, H. E., Barry, C. T., \& Loney, B. R. (2003). Callous-unemotional traits and developmental pathways to severe conduct problems. Developmental Psychology, 39, 246-260.

Frick, P. J., Kimonis, M. S., Dandreaux, D. M., \& Farell, J. M. (2003). The 4-year stability of psychopathic traits in nonreferred youth. Behavioral Sciences and the Law, 21, 713736.

Giedd, J. N., Blumenthal, J., Jeffries, N. O., Castellanos, F. X., Zijdenbos, L. H., Paus, T., Evans, A. C., \& Rapoport, J. L. (1999). Brain development during childhood and adolescence: A longitudinal MRI study. Nature Neuroscience, 2, 861-863.

Goodman, L. A., Dutton, M. A., \& Bennett, L. (2000). Predicting repeat abuse among arrested batterers: Use of the Danger Assessment Scale in the criminal justice system. Journal of Interpersonal Violence, 15, 63-74.

Gretton, H. M., Hare, R. D., \& Catchpole, R. (2004). Psychopathy and offending from adolescence to adulthood: A 10-year follow-up. Journal of Consulting and Clinical Psychology, 72, 636-645.

Gretton, H. M., McBride, M., Hare, R. D., O’Shaughnessy, R., \& Kumka, G. (2001). Psychopathy and recidivism in adolescent sex offenders. Criminal Justice and Behavior, $28,427-449$.

Grisso, T. (1998). Forensic evaluations of juveniles. Sarasota, FL: Professional Resource Press.

Hare, R. D. (1996). Psychopathy: A clinical construct whose time has come. Criminal Justice and Behavior, 23, 25-54.

Hare, R. D. (1998). The Hare PCL-R: Some issues concerning its use and misuse. Legal and Criminological Psychology, $3,99-119$.

Hare, R. D. (2003). The Hare Psychopathy Checklist-Revised (PCL-R), Second Edition technical manual. Toronto, ON: Multi-Health Systems.

Hart, S., Watt, K. A., \& Vincent, G. (2002). Commentary on Seagrave and Grisso: Impressions of the state of the art. Law and Human Behavior, 26, 241-246.

Harris, G. T., Rice, M. E., Quinsey, V. L., Lalumiere, M. L., Boer, D., \& Lang, C. (2003). A Multisite comparison of actuarial risk instruments for sex offenders. Psychological Assessment, 15, 413-425.

Hemphill, J. F., Hare, R. D., \& Wong, S. (1998). Psychopathy and recidivism: A review. Legal and Correctional Psychology, 3, 139-170. 
Herrenkohl, T. I., Hill, K. G., Chung, I., Guo, J., Abbott, R. D., $\&$ Hawkins, D. J. (2003). Protective factors against serious violent behavior in adolescence: A prospective study of aggressive children. Social Work Research, 27, 179-190.

Hoge, R. D., \& Andrews, D. A. (2002). Youth Level of Service/ Case Management Inventory, User's manual. Toronto, Canada, MHS.

Johnstone, L., \& Cooke, D.J. (2004). Psychopathic-like traits in childhood: Conceptual and measurement concerns. Behavioral Sciences and the Law, 22, 103-125.

Kellerman, J. (1999). Savage spawn: Reflection of violent children. New York: Ballantine.

Lambert, E. W., Wahler, R. G., Andrade, A. R., \& Bickman, L. (2001). Looking for the disorder in conduct disorder. Journal of Abnormal Psychology, 110, 110-123.

Leistico, A. M., \& Salekin, R. T. (2003). Testing the reliability and validity of the Risk, Sophistication-Maturity, and Treatment Amenability Instrument (RST-I): An assessment tool for juvenile offenders. International Journal of Forensic Mental Health, 2, 101- 118.

Loeber, R., Farrington, D.P., \& Petechuk, D. (2003). Child delinquency: Early intervention and prevention. Washington, DC: Office of Juvenile Justice and Delinquency Prevention, U.S. Department of Justice. [Available online: http:// www.ncjrs.org/pdffiles1/ojjdp/186162.pdf].

Lynam, D. R. (1998). Early identification of the fledgling psychopath: Locating the psychopathic child in the current nomenclature. Journal of Abnormal Psychology, 107, 566575.

Lynam, D. R. (1997). Pursuing the psychopath: Capturing the fledgling psychopath in a nomological net. Journal of Abnormal Psychology, 106, 425-438.

Lynam, D. R. (1996). Early identification of chronic offenders: Who is the fledging psychopath? Psychological Bulletin, 120, 209-234.

Lynam, D. R., \& Gudonis, L. (2005). The development of psychopathy. Annual Review of Clinical Psychology, 1, 381407.

Marshall, L. A. \& Cooke, D. J. (1999). The childhood experiences of psychopaths: A retrospective study of familial and societal factors. Journal of Personality Disorders, 13, 211-225.

Mash, E. J., \& Dozois, D. J. (2003). Child Psychopathology: A developmental-systems perspective. In E. J. Mash \& R. A. Barkley (Eds.), Child psychopathology (2nd ed., pp. 3-74). New York: The Guilford Press.

Moffitt, T. E., \& Caspi, A. (2001). Childhood predictors differentiate life-course persistent and adolescence limited antisocial pathways among males and females. Development and Psychopathology, 13, 355-375.

Mulvey, E. P., \& Cauffman, E. (2001). The inherent limits of predicting school violence. American Psychologist, 56, 797802.

Patrick, C. J., Hicks, B. M., Krueger, R. F., \& Lang, A. R. (2005). Relations between psychopathy facets and externalizing in a criminal offender sample. Journal of Personality Disorders, 19, 339-356.

Penney, S. R., \& Moretti, M. (2005). The transfer of juveniles to adult court in Canada and the United States: Confused agendas and compromised assessment procedures.
International Journal of Forensic Mental Health, 4, 1937.

Pervin, L. A. (2001). Adynamic systems approach to personality. European Psychologist, 6, 172-176.

Piatigorsky, A., \& Hinshaw, S. P. (2004). Psychopathic traits in boys with and without attention- deficit/hyperactivity disorder: Concurrent and longitudinal correlates. Journal of Abnormal Child Psychology, 32, 535-550.

Porter, S. (1996). Without conscience or without active conscience? The etiology of psychopathy revisited. Aggression and Violent Behavior, 1, 179-189.

Quinn, K. M. (1998). Juveniles on trial. Child \& Adolescent Psychiatric Clinics of North America, 11, 719-730.

Raine, A., Lencz, T., Taylor, K., Hellige, J., Bihrle, S., Lacasse, L., Lee, M., Ishikawa, S., \& Colletti, P. (2003). Corpus callosum abnormalities in psychopathic antisocial individuals. Archives of General Psychiatry, 60, 1134-1142.

Rice, M. E., Harris, G. T., \& Cormier, C. A. (1992). An evaluation of a maximum-security therapeutic community for psychopaths and other mentally disordered offenders. Law and Human Behavior, 16, 399-412.

Rogers, R. (2000). The uncritical acceptance of risk assessments in forensic practice. Law and Human Behavior, 24, 595605.

Rogers, R., Jackson, R., Sewell, K. S., \& Johansen, J. (2004). Predictors of treatment outcome in dually-diagnosed antisocial youth: An initial study of forensic inpatients. Behavioral Sciences and the Law, 22, 215-224.

Rutter, M., \& Stroufe, A. (2000). Developmental psychopathology: Concept and challenges. Development and Psychopathology, 12, 265-296.

Salekin, R. (2002). Psychopathy and therapeutic pessimism: Clinical lore or clinical reality. Clinical Psychology Review, $22,79-112$.

Salekin, R. T., \& Frick, P. J. (2005). Psychopathy in children and adolescents: The need for a developmental perspective. Journal of Abnormal Child Psychology, 33, 403-409.

Salekin, R. T., Rogers, R., \& Sewell, K. W. (1996). A review and meta-analysis of the Psychopathy Checklist and Psychopathy Checklist-Revised: Predictive validity of dangerousness. Clinical Psychology: Science and Practice, 3, 203-215.

Salekin, R. T., Rogers, R., \& Ustad, K. (2001). Juvenile waiver to adult courts: Prototypes for dangerousness, sophistication-maturity, and amenability to treatment. Psychology, Public Policy, and Law, 7, 381- 408.

Schopp, R. F., \& Slain A. J. (2000). Psychopathy, criminal responsibility, and civil commitment as a sexual predator. Behavioral Sciences and the Law, 18, 247-274.

Seagrave, D., \& Grisso, T. (2002). Adolescent development and the measurement of juvenile psychopathy. Law and Human Behavior, 26, 219-240.

Steinberg, L., \& Scott, E. (2003). Less guilty by reason of adolescence: Developmental immaturity, diminished responsibility, and the juvenile death penalty. American Psychologist, 58, 1009-1018.

Viding, E., Blair, R. J. R., Moffitt, T. E., \& Plomin, R. (2005). Evidence for substantial genetic risk for psychopathy in 7year-olds. Journal of Child Psychology and Psychiatry, 46, 592-597. 
Vincent, G., Vitacco, M. J., Grisso, T., \& Corrado, R. R. (2003). Subtypes of adolescent offenders: Affective traits and antisocial behavior problems. Behavioral Sciences and the Law, 21, 695-712.

Vitacco, M. J., Neumann, C. S., \& Jackson, R. (2005). Development of a four-factor model of psychopathy: Associations with ethnicity, gender, violence, and intelligence. Journal of Consulting and Clinical Psychology, 73, 466-476.
Vitacco, M. J., Rogers, R., \& Neumann, C. S. (2003). The Antisocial Process Screening Device: An examination of its construct and criterion-related validity. Assessment, 10, 143-150.

Vitacco, M. J., \& Rogers, R. (2001). Predictors of adolescent psychopathy: The role of impulsivity, hyperactivity, and sensation seeking. Journal of the American Academy of Psychiatry and the Law, 29, 374-386. 